\title{
BMJ Open Frontline interdisciplinary clinician perspectives on caring for patients with COVID-19: a qualitative study
}

\author{
Hassan Rao (D) , ${ }^{1}$ Diana Mancini, ${ }^{1}$ Allison Tong, ${ }^{2}$ Humaira Khan, ${ }^{3}$ \\ Brissa Santacruz Gutierrez, ${ }^{4}$ William Mundo, ${ }^{4}$ Adriana Collings, ${ }^{5}$ Lilia Cervantes ${ }^{1}$
}

To cite: Rao H, Mancini $D$, Tong A, et al. Frontline interdisciplinary clinician perspectives on caring for patients with COVID-19: a qualitative study. BMJ Open 2021;11:e048712. doi:10.1136/ bmjopen-2021-048712

- Prepublication history and supplemental material for this paper is available online. To view these files, please visit the journal online (http://dx.doi. org/10.1136/bmjopen-2021048712).

Received 06 January 2021

Revised 13 April 2021

Accepted 16 April 2021

Check for updates

(C) Author(s) (or their employer(s)) 2021. Re-use permitted under CC BY-NC. No commercial re-use. See rights and permissions. Published by BMJ.

${ }^{1}$ Division of Hospital Medicine, Denver Health, Denver, Colorado, USA

${ }^{2}$ Sydney School of Public Health, The University of Sydney, Sydney, New South Wales, Australia

${ }^{3}$ Indiana University School of Medicine, Indianapolis, Indiana, USA

${ }^{4}$ University of Colorado, Anschutz Medical Campus, Denver, Colorado, USA

${ }^{5}$ Office of Research, Denver Health, Denver, Colorado, USA

Correspondence to

Dr Hassan Rao;

hassan.rao@dhha.org

\section{ABSTRACT}

Objective To describe the drivers of distress and motivations faced by interdisciplinary clinicians who were on the frontline caring for patients with COVID-19. Design 50 semistructured interviews. Transcripts were analysed using qualitative thematic analysis.

Setting A safety-net hospital in Denver, Colorado. Participants Interdisciplinary frontline clinicians including physicians, advance practice providers, nurses, respiratory therapists and paramedics providing inpatient hospital care to patients hospitalised for COVID-19.

Results Fifty clinicians (32 women and 18 men) participated. Five themes with respective subthemes (in parentheses) were identified: depersonalisation and barriers to care (impeding rapport and compassion, focusing on infection risk at the expense of high-quality care, grief from witnessing patients suffer in isolation), powerless in uncertainty (inescapable awareness of personal risk, therapeutic doubt in a void of evidence, confronting ethical dilemmas, struggling with dynamic and unfamiliar challenges), overwhelmed and exhausted (burden of personal protective equipment (PPE), information overload and confusion, overstretched by additional responsibilities at work, compounded by personal life stressors, feeling vulnerable and dispensable, compassion fatigue, distress from the disproportionate impact on socially oppressed communities), bolstering morale and confidence (motivated by community and family support, equipped with data), and driven by moral duty (responsibility to patient care and community, collegial solidarity and collaboration, contributing to the greater good).

Conclusion Frontline clinicians reported distress due to the challenges of PPE, uncertainty and powerlessness, new responsibilities at work and home, losing control of their schedules, grief from witnessing patients suffer in isolation and witnessing healthcare disparities exacerbated by this pandemic. Clinicians feel supported by their colleagues, families, and community and were driven by a sense of moral duty. Healthcare system should adopt strategies to minimise distress faced by interdisciplinary clinicians on the frontline of COVID-19.

\section{INTRODUCTION}

The COVID-19 pandemic has presented unprecedented challenges for the healthcare system. In anticipation of this crisis,

\section{Strengths and limitations of this study}

- This study explored the perspectives of a diverse group of interdisciplinary clinicians including physicians, advance practice providers, nurses, paramedics and respiratory therapists working in a variety of hospital settings including the emergency department, medical/surgical floor and intensive care unit.

- This study generated comprehensive and detailed insights because interviews were conducted until data saturation.

- This study assessed the perspectives of clinicians only; future studies may assess the perspectives of environmental staff and food services as they also interfaced with patients hospitalised for COVID-19.

- This study included a small sample size and interdisciplinary clinicians were recruited from one safety-net centre.

- Transferability of these findings to other hospital settings is uncertain given the unique safety-net patient population, culture and resources available.

healthcare facilities focused on procurement of testing supplies and personal protective equipment (PPE), creating treatment algorithms, ethical resource allocation guidelines, and expanding bed capacity and staffing among other logistics to keep patients and clinicians safe. ${ }^{1-4}$ Despite these efforts to protect clinicians, this pandemic has taken a significant toll on the physical, emotional and mental health of frontline clinicians. ${ }^{2-10}$ Given epidemic levels of burnout prior to this pandemic and reports of suicides among frontline clinicians in New York City, it has become increasingly important to understand the driver of clinician distress through this pandemic. ${ }^{11-13}$

While it is clear that frontline responders to public health emergencies are particularly vulnerable to experiencing acute psychological distress, the underlying drivers of distress can be unique in different populations, cultures, clinical settings and with variable extent of impact and time course. ${ }^{14}$ 
During the SARS pandemic, clinicians experienced distress related to uncertainty and fear of the unknown, stigmatisation from becoming infected, social isolation and conflicting moral obligations to treat patients yet keep their families safe. ${ }^{15-17}$ For some clinicians, this led to long-term mental health problems and burnout. ${ }^{18-20}$ The COVID-19 pandemic is unique due to its unpredictable course and widespread global impact. ${ }^{21}$ Frontline clinicians across the world have experienced similar challenges with supply constraints, staffing shortages and risk of infection. ${ }^{22}$

Despite cultural, political and case rate variances, studies have found high rates of psychological symptoms among clinicians during this pandemic. ${ }^{23-28}$ However, there are limited qualitative data describing the drivers of distress. ${ }^{29-37}$ The aim of this study was to describe the drivers of distress and motivation with the goals of informing local and national strategies to reduce avoidable distress in interdisciplinary clinicians on the frontline of COVID-19.

\section{METHODS}

\section{Study design}

Fifty semistructured interviews were conducted with frontline clinicians. All study participants provided informed verbal consent and received financial compensation. Participants were assigned a study identification number and were informed all information provided would remain confidential.

\section{Patient and public involvement}

It was not appropriate or possible to involve patients or the public in the design of this research.

\section{Setting and participants}

Eligible participants included interdisciplinary frontline clinicians including physicians, advance practice providers, nurses, and paramedics who participated in the care of suspected or confirmed COVID-19-positive patients at Denver Health, a safety-net hospital. Participants were recruited by a standardised, institutional review board-approved email sent by the study principal investigator. The first participants to respond were included and scheduled for interviews. Purposive sampling was used to capture a diverse sample in terms of demographics (sex, age) and clinical discipline. We capped participants within each clinical category to ensure a balanced proportion of clinician training backgrounds and departments.

\section{Data collection}

Semistructured interviews were conducted using a telephone or video-conferencing platform from 22 April to 8 July 2020 by authors HR, DM and LC until data saturation. LC has conducted and published qualitative research and has lectured in qualitative methodology. HR and DM completed training in qualitative research analysis and were mentored by LC. All three of these authors are internal medicine-trained physicians who participated in the frontline of caring for patients hospitalised with COVID-19. The interview guide was based on the literature and discussion among the research team (online supplemental table 1). ${ }^{7-10}{ }^{15-19}$ Interviews were recorded and transcribed verbatim.

\section{Data analysis}

Using thematic analysis, authors HR, DM, AT and LC read the transcripts and inductively identified initial concepts. Author AT grouped similar concepts into themes and subthemes and coded the data using HyperRESEARCH software (V.4.1.1; ResearchWare, Randolph, Massachusetts, USA). Authors HR and LC reviewed and discussed the coding and themes to make sure that the findings reflected the full range and depth of the data.

\section{RESULTS}

The 50 participants included 22 physicians, 18 registered nurses, 4 nationally registered paramedics, 2 respiratory therapists and 4 advance practice providers (two nurse practitioners, one physician assistant and one certified registered nurse anaesthetist), and 1 emergency medical technician. There were $32(64 \%)$ women, $32(64 \%)$ were married and 28 (56\%) had children. Twenty-seven (54\%) lived with frontline clinicians (table 1). The duration of the interviews ranged from 28 to $92 \mathrm{~min}$.

We identified five themes: depersonalisation and barriers to care; powerlessness in uncertainty; physical, emotional and mental exhaustion; bolstering morale and confidence; and driven by moral duty. The subthemes are described below with supporting quotations provided in table 2 .

\section{Depersonalisation and barriers to care Impeding rapport and compassion}

The need to use PPE made it difficult for participants to 'connect with' and establish trust with patients because they could not communicate properly and were unable to 'convey emotion'. The PPE stripped away a core dimension of patient care by taking 'a lot out of the human experience.' Some felt that it was 'like a zoo' because they would 'look through a glass window and talk about a human being without them being involved.'

\section{Focusing on infection risk at the expense of high-quality care}

To minimise exposure, participants spent less time in patient rooms and assessed patients over the phone. Clinicians acknowledged that this was a 'necessary evil', which limited their ability to provide high-quality care. Except for in-person physical examination at the time of admission and discharge, clinicians assessed their patients over the phone only: 'The hardest part is just having very little to offer out of what I would have considered my strongest toolkit.' Some also questioned if they 'missed something'.

\section{Grief from witnessing patients suffer in isolation}

Due to isolation policies, patients were unable to have visitors. Participants felt 'indescribable' grief because 
Table 1 Patient characteristics $(\mathrm{N}=50)$

\begin{tabular}{|c|c|}
\hline Characteristic & $\begin{array}{l}\text { Value } \\
(\mathrm{n}=50)\end{array}$ \\
\hline Age, mean (SD), years & $40.6(8.6)$ \\
\hline Women, no (\%) & $32(64)$ \\
\hline Married, no (\%) & $32(64)$ \\
\hline Dependents, more than 1, no (\%) & $28(56)$ \\
\hline Clinical experience, mean (SD), years & $12.5(8.4)$ \\
\hline At least 2 frontline workers at home, no (\%) & $6(12)$ \\
\hline $\begin{array}{l}\text { Days worked with patients with COVID } 19 \text { in } \\
\text { past month, mean (SD) }\end{array}$ & $11.5(5.1)$ \\
\hline $\begin{array}{l}\text { Patients transferred to ICU in last } 2 \text { weeks, } \\
\text { mean (SD) }\end{array}$ & $4.3(4.3)$ \\
\hline Code blues during last 2 weeks, mean (SD) & $1.4(1.7)$ \\
\hline Deaths during last 2 weeks, mean (SD) & $1.5(2.4)$ \\
\hline Participants with COVID-19, no (\%) & $4(8)$ \\
\hline \multicolumn{2}{|l|}{ Discipline, n (\%) } \\
\hline \multicolumn{2}{|l|}{ Hospital medicine } \\
\hline Physician & $5(10)$ \\
\hline Nurse & $6(12)$ \\
\hline Nurse practitioner & $1(2)$ \\
\hline \multicolumn{2}{|l|}{ Pulmonary/critical care } \\
\hline Physician & $6(12)$ \\
\hline Nurse & $6(12)$ \\
\hline \multicolumn{2}{|l|}{ Emergency medicine } \\
\hline Physician & $4(8)$ \\
\hline Physician assistant & $1(2)$ \\
\hline Nurse practitioner & $1(2)$ \\
\hline Nurse & $5(10)$ \\
\hline Emergency medical technicians & $1(2)$ \\
\hline Nationally registered paramedic & $4(8)$ \\
\hline \multicolumn{2}{|l|}{ Anaesthesiology } \\
\hline Physician & $3(6)$ \\
\hline Certified registered nurse anaesthetist & $1(2)$ \\
\hline Infectious disease physician & $2(4)$ \\
\hline Respiratory therapists & $2(4)$ \\
\hline
\end{tabular}

ICU, intensive care unit.

they could do little to alleviate the terror and loneliness patients suffered. 'The family can't be there; it adds to the sadness of the situation where there's so much isolation... Patients are isolated from pretty much all support systems.' It was also emotionally difficult helping patients communicate with their family-'I had her FaceTime her sister so she could see the baby that she'd never held...I don't cry, that's as close as it gets.' COVID-19 was also considered by some to be 'the worst possible way that someone could die because you're surrounded by air, you cannot breathe.'

\section{Powerless in uncertainty}

Inescapable awareness of personal risk

Initial concerns about infection dissipated with confidence in PPE. However, this 'air of invincibility was easily shattered' as more clinicians became sick and cared for patients who were fit or close to their own age-it's 'scary, because when you look at them, you see your own family members and the potential for the people that you care about in your own life' to suffer the same fate. They were constantly processing 'terrifying' and 'existential questions' that intensified distress. Participants who contracted COVID-19 worried about their own health and their loved ones.

\section{Therapeutic doubt in a void of evidence}

Participants were challenged by uncertainty and guilt stemming from the lack of data to inform prognostication and therapies. Many felt 'powerless' and humbled by the unpredictability of the disease. Some felt like trainees again, 'where everything is new and you think you know what you're doing but you're unsure and have self-doubt.' They accepted that managing COVID-19 was 'a lot of trial and error.' Participants worried about medications that 'weren't proven' and 'that some people ended up on the ventilator that maybe wouldn't have needed to.'

\section{Confronting ethical dilemmas}

Preparing for decisions about rationing resources was 'incredibly stressful.' It was horrifying to consider bearing the responsibility of 'condemning a person to die' and the possibility of having to 'sacrifice a few for the greater good.' Conversations around goals of care were challenging without family members at the bedside; 'it's just hard to really understand what your loved one is going through.' Many clinicians discussed goals of care at the time of admission for all patients regardless of age or comorbidities.

\section{Struggling with dynamic and unfamiliar challenges}

Frequent changes in policies, guidelines and conflicting information created a challenging and chaotic environment. They described how 'every day was a new day. You really had no idea what was happening.' Participants worked in new settings and felt constant anxiety being outside their 'comfort zone.' The uncertain course of the pandemic was challenging as they lost control over their schedules, cancelled vacations and accepted that they 'might be in this for the long haul.'

\section{Overwhelmed and exhausted}

\section{Burden of PPE}

Wearing PPE was exhausting. It was 'difficult to breathe,' 'hot and uncomfortable', and slowed their ability to enter rooms and respond to patient requests for food, water or to use the bathroom. The process of wearing PPE and remembering each step added a new 'cognitive load'. The 'hyperawareness' of risk added stress-'it's led to me feeling like I made some silly mistakes, because I had energy devoted to what my hands just did, "did I just 
Table 2 Selected supporting quotations

Theme Quotations

Depersonalisation and barriers to care

Impeding rapport and compassion

You don't get to know the patient as a person (Physician, 30s)

It just feel very impersonal, when you're used to being very close to people... being able to sit with them ... they can see your whole face, see your expressions... It's challenging... to give people confidence and compassion and just convey to them that you really do care. (Nurse, female, 40s)

The depersonalization of medicine... I feel guilty because I'm not engaged with them on the same humanistic level that I typically would with a patient who is clinically worsening. (Physician, male, 30s)

Focusing on infection risk at the expense of high-quality care

Grief from witnessing patients suffer in isolation
We had a patient who fell, she was my patient. And because she put her call light on, she called appropriately, she was impulsive, but like we were not able to get into to the room fast enough, because we had to put on our gear and she, she fell, like she fell hard. (Nurse, female 30s)

He was brought in, he had tombstone EKGs and he had a massive MI. So, you know, before COVID, shortness of breath in a man you, would think cardiac dyspnea, but it's like, we had these terrible COVID blinders on... I saw a man that had just terrible DKA and he was admitted and he had a cardiac arrest right after that and then suffered a terrible anoxic injury. And... he would have come in earlier if it hadn't been for COVID. (Physician, male, 40s)

Those family members can't be here. That's just really hard to see that when somebody really needs a loving person... So I gave her a great big hug, and I felt her sadness, and that's just something that I will probably carry with me forever. It's just that feeling of loneliness and sadness that you just can't describe... That truly right now is the hardest thing I deal with every day. (Nurse, female, 50s)

I held a tablet up for a patient who was not alert, responsive, and the family was just like just like we love you, Grandpa, stay strong, and I felt like I was intruding. I was heartbroken watching this like moment take place. (Nurse, female, 30s)

He basically just spent the last five days of his life alone, delirious, for which normally we treat delirium with patients' family at the bedside, reorientation. We did none of that. We really provided sub-optimal care and he died in isolation. (Physician, female, 30s)

Powerless in uncertainty

Inescapable awareness of personal risk
And just that kind of reminder that you don't have to be old to get sick, I'm afraid for the patient, I'm afraid for myself. I'm afraid for the people that I care about in my own life. (Nurse, female, 30s) Practising medicine is just difficult and there are uncertainties about supplies and about my own personal safety as a practising physician (Physician, female, 40s) 
Table 2 Continued

Theme Quotations

Therapeutic doubt in a void of evidence

The fact that a medication wasn't proven. We didn't have good data. This was disconcerting. To not know what we should be recommending... We've learned a lesson that these unproven therapies could be harmful. If you're going to do something that's unproven, you should do it within a trial. We could really be doing more harm than good. That was just a lesson I learned. I was just excited to jump on the bandwagon and offer whatever I could and whatever other institutions were doing. (Physician, female, 30s)

It's pretty unpredictable compared to a lot of other things we treat. You might feel like your patient is clinically improving or kind of out of the woods and then suddenly, they take a turn for the worse. And that then relates to how you can talk to a patient because you can't, it's difficult to have 100\% confidence and say, you're going to be fine. You're improving, you're going to continue to improve because that's all probably not true. (Physician, male, 30s)

I have a lot of fear that that we don't know what's going to make them better or not better... there's a lot of times when I leave work that I feel really empty. Like I don't know if I made a difference and It's kind of sad, like I have a lot of sadness. (Nurse, female, 50s)

Confronting ethical dilemmas

So this is a patient who comes in, they're full code, but we don't have the resources and I had to decide if the 88 year old grandma on dialysis gets the ventilator or the 44 year old. And even just the weight that you have to carry if that's your decision right? That you just condemned this person to die and not this person. It's something that I worried a lot about for myself and also for our trainees; that our residents would have to be exposed to this stuff and carry it with them for the rest of their lives. (Physician, male, 40s)

Struggling with dynamic and unfamiliar challenges The uncertainty about the future, not being able to know like 6 months ahead what our schedule is going to be like and it feels like things could change on any given day. (Physician, female, 30s)

I'm constantly out of my comfort zone there's literally like nothing that is routine or second nature for me. My nervous system is like constantly in like flight mode and sweaty when I am running to a patient's room. (Nurse, female, 30)

\section{Overwhelmed and exhausted}

Burden of PPE

It's very different in a nine hour shift with the PPE... it was uncomfortable and that was also fatiguing. That was all new mental energy that had to be expended to do your job. (Physician, male, 40s) Some days I feel really claustrophobic in the mask and it like increases my anxiety. (Nurse, female, 30s) Just the physical nature of having so many patients prone and flipping them and all of that it's physically hard. (Nurse, female, 50s)

Information overload and confusion

We're just burnt out from the constant changing of policies and expectations. (Nurse, female, 40s)

Things are literally changing on like a day to day, hour by hour basis. (Physician, male, 40s)

It was kind of unique part of COVID is that every day you're also kind of battling the news cycle and being aware of that news cycle, you know, so, like getting questions because the president says he takes hydroxychloroquine. (Physician, female, 30s) 
Table 2 Continued

Theme Quotations

Overstretched by additional responsibilities at work

I'm not alone when I'm saying that I'm feeling burnt out and overwhelmed. (Nurse, female, 30s)

The last week that I was on... come straight home for an hour or two and then write notes until midnight, or 1230 and then get up and do it all over again... It was kind of you know, basic like functioning, eat food and then do more work. (Physician, male, 40s)

Calling patients' families at the end of each day because they couldn't have visitors ... and giving them updates for the day and that by itself took a lot of time and was draining and not something that is normally part of our daily routine. (Physician, male, 30s)

Compounded by life stressors

Having to be like quarantined and do homeschooling on top of all that. It's been very difficult. (Nurse, female, 40s)

Should I separate myself? We ultimately decided that, that would be more traumatic and that this is a marathon and not a spring and that separating myself would be more traumatic... We decided that the risk of this being really upsetting and traumatic for the children would be worse. We had to weigh all of this. (Physician, female, 30s)

Feeling vulnerable and dispensable It made me feel dispensable...There's very much a sense of us not being part of the conversation and instead we are just told that this is how things are going to happen. (Physician, female, 40s)

I never felt more vulnerable than this situation has made me feel in healthcare. (Nurse, female, 40s)

If you want to do sort of a war analogy, it feels like all the generals are making decisions for the people that are dying on the field and nobody, you know, without knowing the reality of it... And so, I mean, I would just, I think it would be eye opening for them to have to come in and see, you know, a prone patient core, you know, and just watch. (Female, nurse, 30s)

People are being asked to work more but are not compensated more. Taking more risk despite having loved ones. It hurt a lot of feelings and made people feel unappreciated. (Physician, female, 30s)

Compassion fatigue

My patience is less. And my empathy is less. My empathy meter is low. (Physician assistant, female, 30s)

So the compassion fatigue l've actually experienced has been with the patients that I don't feel need to be there, right? Like, why are you here? Why are you using these resources? You twisted your ankle three weeks ago, you've been walking around fine... but yeah, there's some compassion fatigue towards those kind of people and l'm trying to save whatever emotional response I have left for the people who I feel like needed it, if that make sense. (Nurse practitioner, female, 30s)

I've been much better about it trying to save those emotions for when it matters. So I guess I've been stingier with my feelings, if that makes sense. (Nurse, female 30s) 
Table 2 Continued

\begin{tabular}{|c|c|}
\hline Theme & Quotations \\
\hline $\begin{array}{l}\text { Distress from the disproportionate impact on socially } \\
\text { oppressed communities }\end{array}$ & $\begin{array}{l}\text { At one point every single patient in our unit was COVID positive } \\
\text { and every single one of them had a Hispanic last name and I just } \\
\text { feel a lot of just mixed emotions, probably between sort of anger } \\
\text { and just kind of profound sadness. I'm just so saddened by just } \\
\text { how unfair it seems. (Nurse, female, } 50 \text { s) } \\
\text { I worry a lot about after they leave, sort of depending on their } \\
\text { situation, and their ability to either socially distance or remain } \\
\text { stay or have access to things like that's a big concern. (Physician, } \\
\text { female, 50s) } \\
\text { I took care of the grandfather or like the father who was } \\
\text { 90-something, and his son was on a ventilator, his grandson } \\
\text { was in the ICU as well, and I talked to his daughter-in-law... The } \\
\text { poor family was just like, totally stressed out; and that was really } \\
\text { heartbreaking... There was something about this pandemic in } \\
\text { that, three fourths of everyone was Latino. And to know why } \\
\text { they were getting it, in that they were probably essential workers, } \\
\text { or needing to work, or they were living in homes with multi- } \\
\text { generational kind of situations; that was really sad and most of } \\
\text { them had nothing. The family, they're barely making it, and how } \\
\text { are they going to survive financially? (Physician, female, } 40 \text { s) } \\
\text { To be doing the bulk of my interviews through the glass on the } \\
\text { phone, particularly with Spanish speakers, it was very unsettling } \\
\text { and unsatisfying on a certain level because I just did feel like I } \\
\text { was doing my best, which was really hard. You wonder like, did } \\
\text { you miss something? (Physician, male, } 30 \text { s) }\end{array}$ \\
\hline
\end{tabular}

\section{Bolstering morale and confidence}

Motivated by community and family support

Community support that's been very touching to me just like the people donating food or like donating masks or create a company like donate goggles, (Nurse, female, 30s) It was the fact that like, 'Oh, like, people care about us and recognize that what we're doing right now is important' and that lifted spirits. (Physician, male, 40s)

Equipped with data

I feel like I know what's going on and so that's calming.

(Physician, female, 30s)

I think an organized plan for what we will do if there is a surge or whether we will be needed to cover hospital shifts... That communication is important because it gives us an idea of where we are with the curve and our hospital capacity. (Physician, female, 30s)

We heard the other day we're running low on masks; they're not trying to hide that. They communicate also what this solution is, what the fix is. That's hugely important, that builds trust, we're able to plan for things, know when things are coming. (Nurse, female, 40s)

\section{Driven by moral duty}

A professional obligation that this is what l've trained for. (Physician, female, 30s)

This has been particularly hard on our.... most vulnerable communities ... That kind of gives a little extra motivation to want to like show up and work hard and take really good care of them. (Physician, male, 30s) 
Table 2 Continued

\begin{tabular}{ll}
\hline Theme & Quotations \\
\hline Collegial solidarity and collaboration & $\begin{array}{l}\text { Specialists, nurses-especially nurses - are a lot more willing } \\
\text { to go above and beyond to take care of these people. That } \\
\text { collective, all hands on deck, throughout the hospital, is really } \\
\text { reassuring - everyone pitching in however they can. (Nurse } \\
\text { practitioner, male, 30s) } \\
\text { I want to support my fellow staff and I don't want to leave them } \\
\text { short. (EMT, male, 30s) }\end{array}$ \\
$\begin{array}{ll}\text { When everything is so negative, I do feel that I can be a good } \\
\text { force, I can be at least something positive in all of it. (Nurse, } \\
\text { female, 40s) }\end{array}$ \\
$\begin{array}{l}\text { To be apart of this illness that nobody really understands. From a } \\
\text { scientific background, it is really interesting that we are learning } \\
\text { new stuff, day by day, week by week. (Nurse practitioner, male, } \\
\text { 30s) }\end{array}$
\end{tabular}

DKA, diabetic ketoacidosis; EMT, emergency medical technician; ICU, intensive care unit; MI, myocardial infarction; PPE, personal protective equipment.

use them to touch my face?"' In making decisions about orderings tests (eg, imaging or labs), they considered if they would be exposing their colleagues. Some were worried about using the same masks all day-'it says on the box "one-time use".'

\section{Information overload and confusion}

Some participants felt inundated by information-'it's like drinking out of a fire hydrant.' They had 'informational burnout' and had difficulty processing new information as it was often changing or conflicting. Even outside of work, information about the pandemic was constantly on the news, social media and in conversations with friends-it was 'exhausting'.

\section{Overstretched by additional responsibilities at work}

Participants took on many new tasks such as coordinating internal communications, creating and managing databases, and following up on discharged patients. Many worked additional shifts-'two more weeks of work crammed into four weeks of work.'

\section{Compounded by personal life stressors}

Participants were concerned about infecting their family and considered whether to isolate from their families. Participants with children had new, time-consuming challenges at home including homeschooling and coordinating childcare. Many felt 'worn out' by these responsibilities-'trying to stay normal, to be the mother and the wife... because they [children] don't deserve to get less of me because of what's happening.'

\section{Feeling vulnerable and dispensable}

As participants coped with the stress of additional shifts, responsibilities and risk, some began to feel 'vulnerable'. Some participants felt well supported by their leaders, but others felt a disconnect between clinical and administrative leadership. They felt leaders needed to be more present-'I think it would be eye opening for them to have to come in and see' the unique challenges of providing care in PPE. Some were concerned about the burden of mandatory extra shifts and lack of 'hazard pay'. Hearing about a 'hiring freeze' and seeing colleagues lose their jobs made them feel expendable.

\section{Compassion fatigue}

As the pandemic progressed, clinicians began feeling emotionally overwhelmed and started developing 'compassion fatigue'. The grief of caring for patients with COVID-19 was further amplified by what some clinicians felt was the psychological impact of quarantine on the community. They described seeing higher rates of patients presenting due to domestic violence, depression and suicides. Over time, clinicians began to feel emotionally exhausted and described symptoms of burnout-'my patience is less. My empathy is less.'

\section{Distress from the disproportionate impact on vulnerable communities}

The injustice of COVID-19 was traumatic. Witnessing the disproportionate impact of the pandemic on racial and ethnic minorities as well as other vulnerable communities was devastating. It was 'heartbreaking' to see multiple members of the same minority family hospitalised and critically ill simultaneously. Many expressed immense grief witnessing the impact on communities that may not have the privilege to isolate, 'they were probably essential workers, or needing to work, or they were living in homes with multi-generational' families. They noticed 'a huge disparity between the rich and the poor.'

\section{Bolstering morale and confidence}

Motivated by community and family support

Participants appreciated the 'outpouring of love and support' from the community who contributed food and donated PPE. They also relied on support from their families. 


\section{Equipped with data}

Information could 'reduce stress and anxiety' as it provided a 'picture of where the hospital's standing.' Communicating 'big wins' such as the number of extubations and discharges inspired optimism. Executives provided transparency around PPE supplies, plans for procurement and curated information from clinical trials. This helped many feel safe and informed. They appreciated clinical updates as they did not have 'time or bandwidth to search through articles.'

\section{Driven by moral duty}

Responsibility to patient care and community

Participants were committed to fulfilling their fundamental responsibility of treating patients who 'deserve good care'. They held a 'high level of social justice and responsibility' and strove to care for the 'underserved and impoverished' patients who presented with COVID-19.

\section{Collegial solidarity and collaboration}

Participants felt 'unified around a common goal or a kind of common enemy (SARS-CoV-2)' and were encouraged by 'interdisciplinary collaboration' and 'sharing of knowledge'. They were 'in it together' and needed to 'have each other's back', particularly given the additional staffing required to manage the crisis: 'We lean on each other, we support each other, we expect each other to be there.'

\section{Contributing to the greater good}

Some believed it was their 'responsibility' to contribute to the greater good and to be a 'good and positive force'. They felt stimulated to understand a novel disease and use their training and skills to 'contribute new knowledge' in managing patients with COVID-19 and to be "part of the solution'.

\section{DISCUSSION}

In this study, we report distress and motivations of interdisciplinary clinicians who provided care to hospitalised patients with COVID-19. Clinicians at the frontline of COVID-19 experienced distress from the emotional and physical burden of PPE, increased responsibilities at work and home, witnessing patients dying in isolation and the exacerbation of systemic healthcare disparities. Clinicians also reported feeling fear, guilt and powerlessness stemming from the many uncertainties of this pandemic. Many clinicians described how these emotions progressed to compassion fatigue, vulnerability and exhaustion reflected in the qualitative themes. These findings are consistent with high rates of distress described in quantitative studies during the current pandemic. Clinicians' fears related to risk of infection, uncertainties of the disease and feelings of exhaustion, as well as being driven by a sense of duty and solidarity, are consistent with studies from the SARS pandemic and qualitative data describing experiences of clinicians in Europe and China during the early stage of this pandemic. However, many clinicians described how the emotional challenges of caring for patients with PPE and hospital isolation policies were compounded by the grief of witnessing an exacerbation of systemic healthcare disparities, which has become more apparent in the COVID-19 pandemic.

Increasing workload and loss of a sense of control have been described as powerful contributors to distress that may lead to burnout. ${ }^{38}$ We identified many facets of uncertainty in the context of COVID-19 including being unable to prognosticate the course of the illness, lack of evidence and therapeutics leading to clinical decisional uncertainty, rapidly changing guidelines and policies, unclear risk of infection, the unknown duration and severity of the pandemic, and a loss of control to their schedules. Clinicians were also distressed by feeling helpless and distressed from witnessing patients suffering in isolation. While clinicians adapted to these uncertain circumstances, there is concern for maintaining this resiliency if long-term solutions around managing workload are not identified by leadership.

There is also concern of increased distress in clinicians who provide care to patients who face complex social challenges. ${ }^{4041}$ Clinicians caring for patients with COVID-19 were dismayed and frustrated by how vulnerable groups such as impoverished, racial and ethnic minority communities had disproportionally higher rates of COVID-19 infection than the general population. While it is possible that this impact may be more noticeable in safety-net institutions, several studies have confirmed the increased prevalence and mortality associated with COVID-19 in Latino, black and 'other' ethnicities. ${ }^{42}$ Clinicians felt defeated because there were limited options for safe self-isolation in these communities due to crowded living conditions, use of public transportation and low-wage service jobs. They were frustrated by barriers that precluded in-person language interpreters owing to the limited availability of PPE and having to resort to telephone language interpreters compounding the difficulties of communicating while wearing PPE.

Higher rates of distress during the COVID-19 pandemic have been found among younger age groups, women and nurses (compared with physicians). ${ }^{5-10}$ This may be because young clinicians with children are burdened by increased responsibilities at work and home compounded by losing control and predictability of their work schedules. Nurses in our study encountered many logistical obstacles as they were required to work additional shifts and often spend more time at the bedside resulting in more time wearing PPE, higher risk of exposure and more time spent witnessing patients suffer in isolation.

Our study has key implications to prevent or minimise distress and risk of subsequent burnout in clinicians (table 3). There is an urgent need to address this, as burnout can lead to poor patient outcomes and will impair the ability of the healthcare system to respond to this crisis. ${ }^{43-46}$ We suggest that institutional leadership create clear structures for understanding and addressing 
Table 3 Suggested interventions to support frontline clinicians

\begin{tabular}{|c|c|}
\hline Strategy & Suggested actions or interventions \\
\hline $\begin{array}{l}\text { Acknowledge } \\
\text { and address } \\
\text { concerns }\end{array}$ & $\begin{array}{l}\text { Create a clear reporting structure and mechanism to allow frontline clinicians to voice clinical concerns } \\
\text { Communicate acknowledgement and validation of concerns as well as plans to address concerns } \\
\text { Maintain an active presence by administrative leadership on clinical floors to improve communication and } \\
\text { better understand frontline clinician challenges } \\
\text { Minimise or consider suspending productivity reports and measurements }\end{array}$ \\
\hline $\begin{array}{l}\text { Reduce clinical } \\
\text { uncertainty }\end{array}$ & $\begin{array}{l}\text { Establish mechanisms for knowledge sharing and delivering emerging clinical research updates } \\
\text { Create and maintain clinical diagnostic and therapeutic guidelines }\end{array}$ \\
\hline $\begin{array}{l}\text { Reduce } \\
\text { infection risk }\end{array}$ & $\begin{array}{l}\text { Maintain adequate supplies of PPE } \\
\text { Allow rapid access for employee testing and occupational health support } \\
\text { Provide information and resources on best practices to minimise infection risk for family members of } \\
\text { clinicians }\end{array}$ \\
\hline $\begin{array}{l}\text { Bolster } \\
\text { psychological } \\
\text { support }\end{array}$ & $\begin{array}{l}\text { Validate and communicate understanding of expected psychological distress } \\
\text { Train providers on applying psychological first aid } \\
\text { Establish one-on-one check-ins with clinicians to screen for severe distress and burnout } \\
\text { Develop programmes that allow clinicians reprieve while on clinical shifts } \\
\text { Engage clinicians in counselling by creating opportunities for peer-to-peer support } \\
\text { Increase access to professional psychological counselling }\end{array}$ \\
\hline $\begin{array}{l}\text { Improve } \\
\text { workload } \\
\text { management } \\
\text { and quality of } \\
\text { patient care }\end{array}$ & $\begin{array}{l}\text { Offer childcare solutions for frontline clinicians } \\
\text { Ensure adequate staffing and create a threshold to hire additional clinicians in anticipation of surging } \\
\text { demand } \\
\text { Limit the number of days or consecutive weeks worked } \\
\text { Allow for breaks from COVID-19 wards } \\
\text { Allow and provide adequate training for clinicians to cross-train in units with increasing demand }\end{array}$ \\
\hline
\end{tabular}

PPE, personal protective equipment.

concerns of frontline clinicians, communicate contingency staffing plans to manage workload and allow frontline clinicians to regain a sense of control of their schedules. Studies have also shown that it is important to support workers' childcare needs during crisis situations. ${ }^{478}$ We recognise that clinicians may not engage in psychological services on their own accord, and therefore suggest that institutions offer proactive psychological counselling and establish peer-to-peer support mechanisms as these provide the most benefit. ${ }^{49-52}$ Finally, it is critical to address structural racism and healthcare disparities as this is an important driver of distress highlighted by this pandemic. This includes improving access to testing, equitable resource allocation, enhanced outreach programmes for minority communities, improved access to in-person translation services and cultural humility training for all staff.

\section{LIMITATIONS}

Our study generated detailed insights on the experiences among frontline clinicians caring for patients with COVID-19. However, our study has some potential limitations. Clinicians were from one academic safety-net hospital in Colorado, thus the transferability of the findings to other settings is uncertain. Studies have shown variances in PPE use among different countries and cultures. Our findings of distress related to the burden of PPE use may not be consistent with clinician experiences in other cultures. ${ }^{53}$ As this study was performed at the early phase of the COVID-19 pandemic, it is also possible that clinician experiences have changed with anticipation of new therapies and the possibility of a vaccine.

Future research is needed to assess the effectiveness of strategies to screen for and reduce psychological distress. While it is clear that clinicians experiencing distress will 
benefit from multifaceted psychological support, ideal implementation strategies to engage and support clinicians are unclear. ${ }^{54}$ There is also limited knowledge of the effectiveness of online-based counselling which can be implemented more readily and has been used to support clinicians in China. ${ }^{22} 55$

\section{CONCLUSION}

Frontline clinicians caring for patients with COVID-19 experience distress related to challenges of PPE, clinical uncertainty and powerlessness, new responsibilities at work and home, losing control of their schedules, and grief from witnessing patients suffer in isolation and witnessing healthcare disparities exacerbated by this pandemic. Providers feel supported by their colleagues, families, and community and were driven by a sense of moral duty. Institutions should further support frontline clinicians by making efforts to understand and address their challenges, provide proactive mental health support and advocate vulnerable communities.

Contributors Authors HR, DM, AT and LC contributed to the conception, design, acquisition and interpretation of the data. Author HR drafted the work, while authors HR, DM, LC, AT and HK revised the work with critically important concepts. Authors HK, BSG and WM contributed to critically important data acquisition and interpretation. Authors AT and AC contributed to data analysis. Authors HR, DM, AT and LC contributed to the final approval of the version published and ensured that questions related to the accuracy or integrity of any part of the work are appropriately investigated and resolved.

Funding The authors have not declared a specific grant for this research from any funding agency in the public, commercial or not-for-profit sectors.

Competing interests None declared.

Patient consent for publication Not required.

Ethics approval This study was approved by the University of Colorado MultiInstitutional Review Board \#20-0709.

Provenance and peer review Not commissioned; externally peer reviewed.

Data availability statement Data are available upon reasonable request. All data relevant to the study are included in the article or uploaded as supplemental information. The relevant data including relevant quotations are contained within the manuscript file. Raw data (full transcriptions of interviews) are stored on an encrypted, secure hospital network and can be reproduced upon request.

Supplemental material This content has been supplied by the author(s). It has not been vetted by BMJ Publishing Group Limited (BMJ) and may not have been peer-reviewed. Any opinions or recommendations discussed are solely those of the author(s) and are not endorsed by BMJ. BMJ disclaims all liability and responsibility arising from any reliance placed on the content. Where the content includes any translated material, BMJ does not warrant the accuracy and reliability of the translations (including but not limited to local regulations, clinical guidelines, terminology, drug names and drug dosages), and is not responsible for any error and/or omissions arising from translation and adaptation or otherwise.

Open access This is an open access article distributed in accordance with the Creative Commons Attribution Non Commercial (CC BY-NC 4.0) license, which permits others to distribute, remix, adapt, build upon this work non-commercially, and license their derivative works on different terms, provided the original work is properly cited, appropriate credit is given, any changes made indicated, and the use is non-commercial. See: http://creativecommons.org/licenses/by-nc/4.0/.

ORCID iD

Hassan Rao http://orcid.org/0000-0002-9102-2242

\section{REFERENCES}

1 Liu Y, Li J, Feng Y. Critical care response to a hospital outbreak of the 2019-nCoV infection in Shenzhen, China. Crit Care 2020;24:56.

2 Liew MF, Siow WT, MacLaren G, et al. Preparing for COVID-19: early experience from an intensive care unit in Singapore. Crit Care 2020;24:83.

3 Chopra V, Toner E, Waldhorn R, et al. How should U.S. hospitals prepare for coronavirus disease 2019 (COVID-19)? Ann Intern Med 2020:172:621-2.

4 Wee LE, Fua T-P, Chua YY, et al. Containing COVID-19 in the emergency department: the role of improved case detection and segregation of suspect cases. Acad Emerg Med 2020;27:379-87.

5 Lai J, Ma S, Wang Y, et al. Factors associated with mental health outcomes among health care workers exposed to coronavirus disease 2019. JAMA Netw Open 2020;3:e203976.

6 Rossi R, Socci V, Pacitti F, et al. Mental health outcomes among frontline and second-line health care workers during the coronavirus disease 2019 (COVID-19) pandemic in Italy. JAMA Netw Open 2020;3:e2010185.

7 Zhang W-R, Wang K, Yin L, et al. Mental health and psychosocial problems of medical health workers during the COVID-19 epidemic in China. Psychother Psychosom 2020;89:242-50.

8 Wu W, Zhang Y, Wang P. Psychological stress of medical staffs during outbreak of COVID-19 and adjustment strategy. J Med Virol 2020;92:1962-70.

9 Cai H, Tu B, Ma J, et al. Psychological Impact and Coping Strategies of Frontline Medical Staff in Hunan Between January and March 2020 During the Outbreak of Coronavirus Disease 2019 (COVID-19) in Hubei, China. Med Sci Monit 2020;26:e924171.

10 Mo Y, Deng L, Zhang L, et al. Work stress among Chinese nurses to support Wuhan in fighting against COVID-19 epidemic. J Nurs Manag 2020;28:1002-9.

11 National Academies of Sciences, Engineering, and Medicine. Taking action against clinician burnout: a systems approach to professional well-being. Washington, DC: National Academies Press, 2019.

12 Watkins A, Rothfeld M, Rashbaum W, et al. Doctor who treated virus patients dies by suicide, 2020. Available: <https://www.nytimes. com/2020/04/27/nyregion/new-york-city-doctor-suicide-coronavirus. $\mathrm{html}>$ [Accessed 8 Aug 2020].

13 et alEdelman S, Moore T, Narizhnaya K. EMT john mondello kills himself after less than three months on the job [online] New York Post, 2020. Available: <https://nypost.com/2020/04/25/nyc-emtcommits-suicide-with-gun-belonging-to-his-dad/> [Accessed 8 Aug 2020].

14 Belfroid E, van Steenbergen J, Timen A, et al. Preparedness and the importance of meeting the needs of healthcare workers: a qualitative study on Ebola. J Hosp Infect 2018;98:212-8.

15 Maunder R, Hunter J, Vincent L, et al. The immediate psychological and occupational impact of the 2003 SARS outbreak in a teaching hospital. CMAJ 2003;168:1245-51.

16 Nickell LA, Crighton EJ, Tracy CS, et al. Psychosocial effects of SARS on hospital staff: survey of a large tertiary care institution. CMAJ 2004;170:793-8.

17 Maunder RG, Lancee WJ, Rourke S, et al. Factors associated with the psychological impact of severe acute respiratory syndrome on nurses and other hospital workers in Toronto. Psychosom Med 2004;66:938-42.

18 Wu P, Fang Y, Guan Z, et al. The psychological impact of the SARS epidemic on hospital employees in China: exposure, risk perception, and altruistic acceptance of risk. Can J Psychiatry 2009;54:302-11.

19 Maunder RG, Lancee WJ, Balderson KE, et al. Longterm psychological and occupational effects of providing Hospital healthcare during SARS outbreak. Emerg Infect Dis 2006;12:1924-32.

20 Lancee WJ, Maunder RG, Goldbloom DS. Coauthors for the impact of SARS study. prevalence of psychiatric disorders among Toronto hospital workers one to two years after the SARS outbreak. Psychiatr Serv 2008;59:91-5.

21 Wu Y-C, Chen C-S, Chan Y-J. The outbreak of COVID-19: an overview. J Chin Med Assoc 2020;83:217-20.

22 Kang L, Li Y, Hu S, et al. The mental health of medical workers in Wuhan, China dealing with the 2019 novel coronavirus. Lancet Psychiatry 2020;7:e14.

23 Chew NWS, Ngiam JN, Tan BY-Q, et al. Asian-Pacific perspective on the psychological well-being of healthcare workers during the evolution of the COVID-19 pandemic. BJPsych Open 2020;6:e116.

24 Tan YQ, Wang Z, Yap QV, et al. Psychological health of surgeons in a time of COVID-19. Ann Surg 2021

25 Chew NWS, Lee GKH, Tan BYQ, et al. A multinational, multicentre study on the psychological outcomes and associated physical 
symptoms amongst healthcare workers during COVID-19 outbreak. Brain Behav Immun 2020;88:30523-7.

26 Zhang SX, Liu J, Afshar Jahanshahi A, et al. At the height of the storm: healthcare staff's health conditions and job satisfaction and their associated predictors during the epidemic peak of COVID-19. Brain Behav Immun 2020;87:144-6.

27 Preti E, Di Mattei V, Perego G, et al. The psychological impact of epidemic and pandemic outbreaks on healthcare workers: rapid review of the evidence. Curr Psychiatry Rep 2020;22:43.

28 Luo M, Guo L, Yu M, et al. The psychological and mental impact of coronavirus disease 2019 (COVID-19) on medical staff and general public - A systematic review and meta-analysis. Psychiatry Res 2020;291:113190.

29 Liu Q, Luo D, Haase JE, et al. The experiences of health-care providers during the COVID-19 crisis in China: a qualitative study. Lancet Glob Health 2020;8:e790-8.

30 Sun N, Wei L, Shi S, et al. A qualitative study on the psychological experience of caregivers of COVID-19 patients. Am J Infect Control 2020;48:592-8.

31 Sterling MR, Tseng E, Poon A, et al. Experiences of home health care workers in New York City during the coronavirus disease 2019 pandemic: a qualitative analysis. JAMA Intern Med 2020 doi:10.1001/jamainternmed.2020.3930

32 Aughterson H, McKinlay AR, Fancourt D, et al. Psychosocial impact on frontline health and social care professionals in the UK during the COVID-19 pandemic: a qualitative interview study. BMJ Open 2021;11:e047353.

33 Vindrola-Padros C, Andrews L, Dowrick A, et al. Perceptions and experiences of healthcare workers during the COVID-19 pandemic in the UK. BMJ Open 2020;10:e040503.

34 Vera San Juan N, Aceituno D, Djellouli N, et al. Mental health and well-being of healthcare workers during the COVID-19 pandemic in the UK: contrasting guidelines with experiences in practice. BJPsych Open 2020;7:e15.

35 Hörold M, Drewitz K, Brunnthaler V. "This is really like waiting for war and this is not good" - Intertwining between pandemic experiences, and the development of professional action of healthcare professionals in critical care at the beginning of the COVID-19 pandemic in Germany: a qualitative study. medRxiv.

36 Hoernke K, Djellouli N, Andrews L, et al. Frontline healthcare workers' experiences with personal protective equipment during the COVID-19 pandemic in the UK: a rapid qualitative appraisal. BMJ Open 2021;11:e046199.

37 Bennett P, Noble S, Johnston S, et al. COVID-19 confessions: a qualitative exploration of healthcare workers experiences of working with COVID-19. BMJ Open 2020;10:e043949.

38 Southwick FS, Southwick SM. The loss of a sense of control as a major contributor to physician burnout: a neuropsychiatric pathway to prevention and recovery. JAMA Psychiatry 2018;75:665-6.

39 Freeborn DK. Satisfaction, commitment, and psychological wellbeing among HMO physicians. West J Med 2001;174:13-18.
40 Cervantes L, Richardson S, Raghavan R, et al. Clinicians' perspectives on providing emergency-only hemodialysis to Undocumented immigrants: a qualitative study. Ann Intern Med 2018;169:78-86.

41 Hayashi AS, Selia E, McDonnell K. Stress and provider retention in underserved communities. J Health Care Poor Underserved 2009;20:597-604.

42 Dorn Avan, Cooney RE, Sabin ML. COVID-19 exacerbating inequalities in the US. Lancet 2020;395:1243-4.

43 Munnangi S, Dupiton L, Boutin A, et al. Burnout, perceived stress, and job satisfaction among trauma nurses at a level I safety-net trauma center. J Trauma Nurs 2018;25:4-13.

44 Fahrenkopf AM, Sectish TC, Barger LK, et al. Rates of medication errors among depressed and burnt out residents: prospective cohort study. BMJ 2008;336:488-91.

45 West CP, Tan AD, Habermann TM, et al. Association of resident fatigue and distress with perceived medical errors. JAMA 2009;302:1294-300.

46 Shanafelt TD, Balch CM, Bechamps G, et al. Burnout and medical errors among American surgeons. Ann Surg 2010;251:995-1000.

47 Shanafelt T, Ripp J, Trockel M. Understanding and addressing sources of anxiety among health care professionals during the COVID-19 pandemic. JAMA 2020;323:2133-4.

48 Charney RL, Rebmann T, Flood RG. Emergency childcare for hospital workers during disasters. Pediatr Emerg Care 2015;31:839-43.

49 Maunder RG, Leszcz M, Savage D, et al. Applying the lessons of SARS to pandemic influenza: an evidence-based approach to mitigating the stress experienced by healthcare workers. Can J Public Health 2008;99:486-8.

50 Brooks SK, Webster RK, Smith LE, et al. The psychological impact of quarantine and how to reduce it: rapid review of the evidence. Lancet 2020;395:912-20.

51 Brooks SK, Dunn R, Amlôt $\mathrm{R}$, et al. A systematic, thematic review of social and occupational factors associated with psychological outcomes in healthcare employees during an infectious disease outbreak. J Occup Environ Med 2018;60:248-57.

52 Chen Q, Liang M, Li Y. Mental health care for medical staff in China during the COVID-19 outbreak [published correction appears in Lancet Psychiatry. Lancet Psychiatry 2020;7:e15-16.

53 Wang C, Chudzicka-Czupała A, Grabowski D, et al. The association between physical and mental health and face mask use during the COVID-19 pandemic: a comparison of two countries with different views and practices. Front Psychiatry 2020;11:569981.

54 Pollock A, Campbell P, Cheyne J, et al. Interventions to support the resilience and mental health of frontline health and social care professionals during and after a disease outbreak, epidemic or pandemic: a mixed methods systematic review. Cochrane Database Syst Rev 2020;11:CD013779.

55 Liu S, Yang L, Zhang C, et al. Online mental health services in China during the COVID-19 outbreak. Lancet Psychiatry 2020;7:e17-18. 